\title{
Nanoporous Alumina Membranes for Sugar Industry: An Investigation of Sintering Parameters Influence onUltrafiltration Performance
}

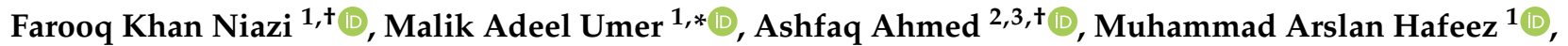 \\ Zafar Khan ${ }^{1}$, Muhammad Shoaib Butt ${ }^{1}$, Abdul Razzaq ${ }^{3}$, Xian Luo ${ }^{4}$ and Young-Kwon Park ${ }^{2, *}$
}

1 School of Chemical and Materials Engineering (SCME), National University of Sciences and Technology (NUST), Sector H-12, Islamabad 44000, Pakistan; mfarooq.me09@scme.nust.edu.pk (F.K.N.); muhammad_arslanhafeez@yahoo.com (M.A.H.); zafar_me06@scme.nust.edu.pk (Z.K.); muhammad.shoaib@scme.nust.edu.pk (M.S.B.)

2 School of Environmental Engineering, University of Seoul, Seoul 02504, Korea; ashfaqengr97@gmail.com

3 Department of Chemical Engineering, COMSATS University Islamabad, Lahore Campus, Defence Road, Off Raiwind Road, Lahore 54000, Pakistan; abdulrazzaq@cuilahore.edu.pk

4 State Key Lab of Solidification Processing, Northwestern Polytechnical University, Xi'an 710072, China; luoxian@nwpu.edu.cn

* Correspondence: umer.adeel@scme.nust.edu.pk (M.A.U.); catalica@uos.ac.kr (Y.-K.P.)

+ Co- First authors.

Citation: Niazi, F.K.; Umer, M.A.; Ahmed, A.; Hafeez, M.A.; Khan, Z.; Butt, M.S.; Razzaq, A.; Luo, X.; Park, Y.-K. Nanoporous Alumina

Membranes for Sugar Industry: An Investigation of Sintering Parameters Influence onUltrafiltration Performance. Sustainability 2021, 13, 7593. https://doi.org/10.3390/ su13147593

Academic Editors: Changhyun Roh, Attila Gere and Marc A. Rosen

Received: 5 June 2021

Accepted: 3 July 2021

Published: 7 July 2021

Publisher's Note: MDPI stays neutral with regard to jurisdictional claims in published maps and institutional affiliations.

Copyright: (c) 2021 by the authors. Licensee MDPI, Basel, Switzerland. This article is an open access article distributed under the terms and conditions of the Creative Commons Attribution (CC BY) license (https:// creativecommons.org/licenses/by/ $4.0 /)$.

\begin{abstract}
Ultrafiltration membranes offer a progressive and efficient means to filter out various process fluids. The prime factor influencing ultrafiltration to a great extent is the porosity of the membranes employed. Regarding membrane development, alumina membranes are extensively studied due to their uniform porosity and mechanical strength. The present research work is specifically aimed towards the investigation of nanoporous alumina membranes, as a function of sintering parameters, on ultrafiltration performance. Alumina membranes are fabricated by sintering at various temperatures ranging from $1200-1300{ }^{\circ} \mathrm{C}$ for different holding times between 5-15 h. The morphological analysis, conducted using Scanning electron microscopy (SEM), revealed a homogeneous distribution of pores throughout the surface and cross-section of the membranes developed. It was observed that an increase in the sintering temperature and time resulted in a gradual decrease in the average pore size. A sample with an optimal pore size of $73.65 \mathrm{~nm}$ achieved after sintering at $1250^{\circ} \mathrm{C}$ for $15 \mathrm{~h}$, was used for the evaluation of ultrafiltration performance. However, the best mechanical strength and highest stress-bearing ability were exhibited by the sample sintered at $1300{ }^{\circ} \mathrm{C}$ for $5 \mathrm{~h}$, whereas the sample sintered at $1250{ }^{\circ} \mathrm{C}$ for $5 \mathrm{~h}$ displayed the highest strain in terms of compression. The selected alumina membrane sample demonstrated excellent performance in the ultrafiltration of sugarcane juice, compared to the other process liquids.
\end{abstract}

Keywords: Ultrafiltration; nanoporous membrane; sintering; time-motion study; sugar industry

\section{Introduction}

Porous materials, such as porous silica [1], $\mathrm{TiO}_{2}$ nanotubes [2-4], and porous alumina [5], have attracted significant interest due to their superior properties. These materials have been extensively explored for use in various applications, including catalysis, healthcare, gas separation, optics, energy, drug delivery, and filtration membranes [6-10]. A membrane is a selective barrier that permits particular molecules/ions to pass through by a combination of diffusion and/or sieving mechanisms [11]. Membranes can be polymeric or ceramics and can be permeable, semi-permeable, and impermeable [12]. Currently, polymers are the leading candidate materials for membranes, but they possess a variety of limitations, such as low fluxes, a low mechanical strength, a proclivity to bio-fouling, and a restricted chemical and thermal stability [13]. In all applications, where the use of 
polymeric membranes is unsuitable and inapplicable, ceramics membranes are used due to their higher mechanical strength, superior thermal, chemical stability [14,15], corrosion resistance [16], and high-pressure resistance [17].

Ceramic membranes have reportedly been fabricated from inorganic materials, including oxides, such as titania $\left(\mathrm{TiO}_{2}\right)$ [18], zirconia $\left(\mathrm{ZrO}_{2}\right)$ [19], and alumina $\left(\mathrm{Al}_{2} \mathrm{O}_{3}\right)$ [20], and non-oxide materials, such as silicon nitride and silicon carbide [21]. Among these, alumina membranes are widely preferred due to their lower cost, easier fabrication, reverse cleaning ability, high trans-membrane pressures, and high mechanical strength [22]. Due to the lower sensitivity of re-hydroxylation, the covalent bonding of the membranes permits the utilization of strong chemicals as reported in the literature [23,24]. Alumina membranes also possess hydrophilic properties due to the presence of hydroxyl $(\mathrm{OH})$ groups, which support water adsorption and prevent the growth of microorganisms on the membrane surface [25]. These properties make alumina a choice of material for microfiltration and ultrafiltration applications, including wastewater treatment [16], biotechnology, increasing the concentration of bio-macromolecules, protein separation [26], hydrogen separation [27], and food processing [28]. Alumina membranes can be fabricated by extrusion, slip casting, and powder pressing [29]. The sugar industry faces several problems in the filtration of various liquids due to the use of conventional filtration processes [30]. During conventional filtration, an inadequate removal of substances, such as gum, silica, ash, among others, during clarification leads to a compromise in the quality and colour of the final product. Additionally, a greater number of steps are required to refine the sugar completely, thus consuming higher amounts of energy. Ultrafiltration membranes find a use in different areas in the sugar industry. Some of these areas include the ultrafiltration treatment of juice after the addition of milk of lime, ultrafiltration treatment after evaporation, and ultrafiltration treatment of raw sugarcane juice [31-33]. The ultrafiltration of sugarcane juice through ceramic membranes, after liming, is considered a relatively new concept in sugar industries, belonging to developing countries. This process offers several advantages in terms of the clarification and concentration of the turbid and multi-component sugarcane juice solution [34-36]. These advantages include complete purification by the removal of substances with high molecular weights (fat, starch waxes, and bacteria), better filtration before evaporation, and a significant increment in the quality of the product. Lee et. al. [28] reported a $53 \%$ increase in the discoloration of sugar syrup using ceramic ultrafiltration in comparison to the conventional refining process. The higher temperature and chemical stability, low maintenance requirements, and fouling resistance of ceramic membranes allow for longer life cycle costs associated with infiltration systems. A lot of useful literature can be found that reports the effects of different materials and dopants on the mechanical, filtration, and anti-fouling properties of ceramic membranes, and fundamental studies that focus on the effects of sintering parameters on the mechanical and filtration performance of alumina membranes are hard to find.

Therefore, this works aims to investigate the effects of processing parameters on the ultrafiltration performance of nanoporous alumina membranes for the sugar industry. Alumina membranes were fabricated through pressureless sintering at various temperatures for different soaking times. The results of scanning electron microscopy (SEM) were used to evaluate the microstructure of the fabricated membranes. Compression and micro-vickers hardness tests were performed to analyse the mechanical properties. A time-motion study and flow rate testing were also carried out by passing sugarcane, distilled water, tap water, and muddy water through the fabricated membranes. 


\section{Materials and Methods}

\subsection{Material and Its Characterization}

The alumina nano-powder was obtained from Chengdu Best New Materials Co. Ltd. Chengdu, China. The morphology and particle size of the obtained alumina nano-powder were analyzed by SEM (Tescan Vega3, France). To validate the particle size, particle size analysis (PSA) was performed using a laser scattering particle size analyzer (Horiba Laser scattering particle size distribution analyzer LA-920, Japan). XRD analysis was also performed to validate the purity of the alumina nano-powder through an X-ray diffractometer (STOE Theta/Theta, Germany), equipped with $\mathrm{K}_{\beta}$ radiation and fluorescence filters, using $\mathrm{CuK}_{\alpha}$ radiations of wavelength $1.5418 \AA$. A step scan mode, with a step size of 0.020 and a scan rate of $0.1 \mathrm{~s}$, was used to obtain the diffraction patterns in the $2 \theta$ range of $20^{\circ}-70^{\circ}$. The XRD spectrum was interpreted by the Xpert High Score Plus software.

\subsection{Fabrication of Aluminamembranes}

Alumina nano-powder with a mean size of $50 \mathrm{~nm}$ was used to fabricate alumina membranes. Green compacts of alumina powder were prepared by pressing $1.5 \mathrm{~g}$ of alumina nano-powder in a mild steel die with low tolerances under a uniaxial pressure of $150 \mathrm{MPa}$ for $1 \mathrm{~min}$ through a hydraulic press (Viv Tek, CIP T20-E, USA) into dimensions of $25.4 \mathrm{~mm}$ diameter and $2 \mathrm{~mm}$ thickness. The green compacts were then sintered in a muffle furnace (Nobertherm GmbH, Germany) at various temperatures and soaking times, as shown in Table 1. After sintering, all samples were cooled to room temperature and prepared for subsequent characterization.

Table 1. Compressive properties of alumina membranes, fabricated by sintering.

\begin{tabular}{ccc}
\hline Sample ID & Max Stress (MPa) & Max Strain (\%) \\
\hline $1200-5 \mathrm{~h}$ & 0.206 & 2.404 \\
$1250-5 \mathrm{~h}$ & 0.141 & 3.694 \\
$1250-15 \mathrm{~h}$ & 0.373 & 2.195 \\
$1300-5 \mathrm{~h}$ & 0.4881 & 2.272 \\
\hline
\end{tabular}

\subsection{Scanning Electron Microscopy}

To analyze their morphology using SEM, all the fabricated alumina samples were prepared by polishing on diamond paste coated $(1$ and $0.25 \mu \mathrm{m})$ nylon and velvet cloths using an electric polisher (Ecomet 250 Grinder/Polisher USA). Before examining the surface morphologies, the samples were gold sputtered (purity $99.99 \%$, thickness $15 \mathrm{~nm}$ ) to obtain high-quality micrographs. The gold-sputtered samples were then analyzed (Tescan Vega 3 , France), and micrographs were captured from both the surface and cross-section at $5000 \times$ magnification. The pore sizes at both the surface and cross-section of the alumina membranes were also measured using software (Digital micrograph).

\subsection{Compression Testing}

To evaluate the effect of applied pressure during ultrafiltration, compression testing was performed on all the fabricated samples. Compression testing was carried out on samples with dimensions that adhere to the ASTM B-925 standard using a universal testing machine (Tinius Olsen, Super 602L, UK), equipped with a $300 \mathrm{KN}$ load cell and extensometer, at a strain rate of $0.005 \mathrm{~mm} / \mathrm{min}$.

\subsection{Micro Vickers Hardness Testing}

Vickers hardness testing was performed on all samples, ground, and polished by the aforementioned procedure. The tests were carried out on a micro Vickers hardness tester (Tinius Olsen, FH-006, UK), equipped with a diamond indenter, under a load of $1 \mathrm{~kg}$ (ASTM E 92), applied for $10 \mathrm{sec}$. Five readings were taken and averaged to obtain the final value for each sample. 


\subsection{Lab-Scale Ultrafiltration Analysis Setup}

To analyze the ultrafiltration performance, the ultrafiltration analysis setup was developed at a lab scale. Conceptual drawing, as well as an image of the Teflon fabricated membrane holding device, are illustrated in Figure 1, whereas the schematics of the piping and instrumentation of the setup are illustrated in Figures 2 and 3, respectively. Alumina membranes of pore sizes up to $100 \mathrm{~nm}$ have been reported to provide an excellent ultrafiltration performance [35]. Therefore, a membrane sample of $25.4 \mathrm{~mm}$ diameter, $2 \mathrm{~mm}$ thickness, and lowest pore size of $73.65 \mathrm{~nm}$, fabricated by sintering at $1250{ }^{\circ} \mathrm{C}$ for $15 \mathrm{~h}$, was selected as a filter. To provide safe accommodation to the filter (alumina membrane) and ensure airtightness and leak-proof operation at high pressures, rubber O-rings were applied where necessary.
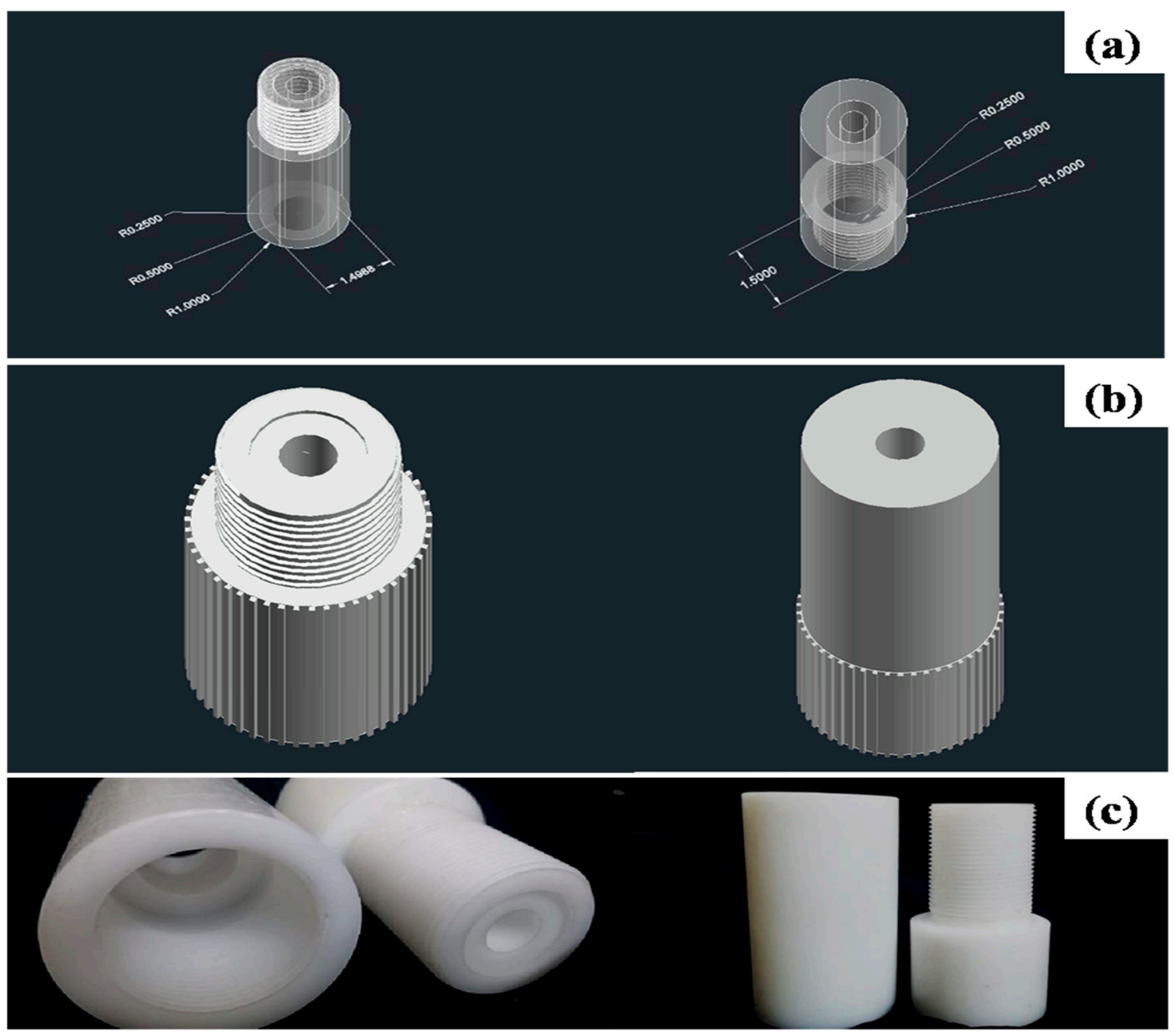

Figure 1. (a) AutoCad conceptual drawing (top and bottom), (b) finalized membrane holding device design, and (c) Teflon fabricated membrane holding device.

High vacuum silicone grease was used for the airtight fixation of the filter and to ensure that the unfiltered solution only flows directly through the alumina filter and not through the crevices between the alumina filter and the holder at the point of fixation. Hose clamps were used for the installation of rubber pipes and valves, including valve 1 , valve 2 , and rotating valve, in the setup. For sealing the joints in the steel fittings, Teflon tape was used. The lab-scale ultrafiltration setup was designed for a pressure of $4-8$ bars. To provide this pressure, an air compressor of $12 \mathrm{~V}$ and $10 \mathrm{~A}$, equipped with a digital pressure controller and a separate pressure gauge, was used. 


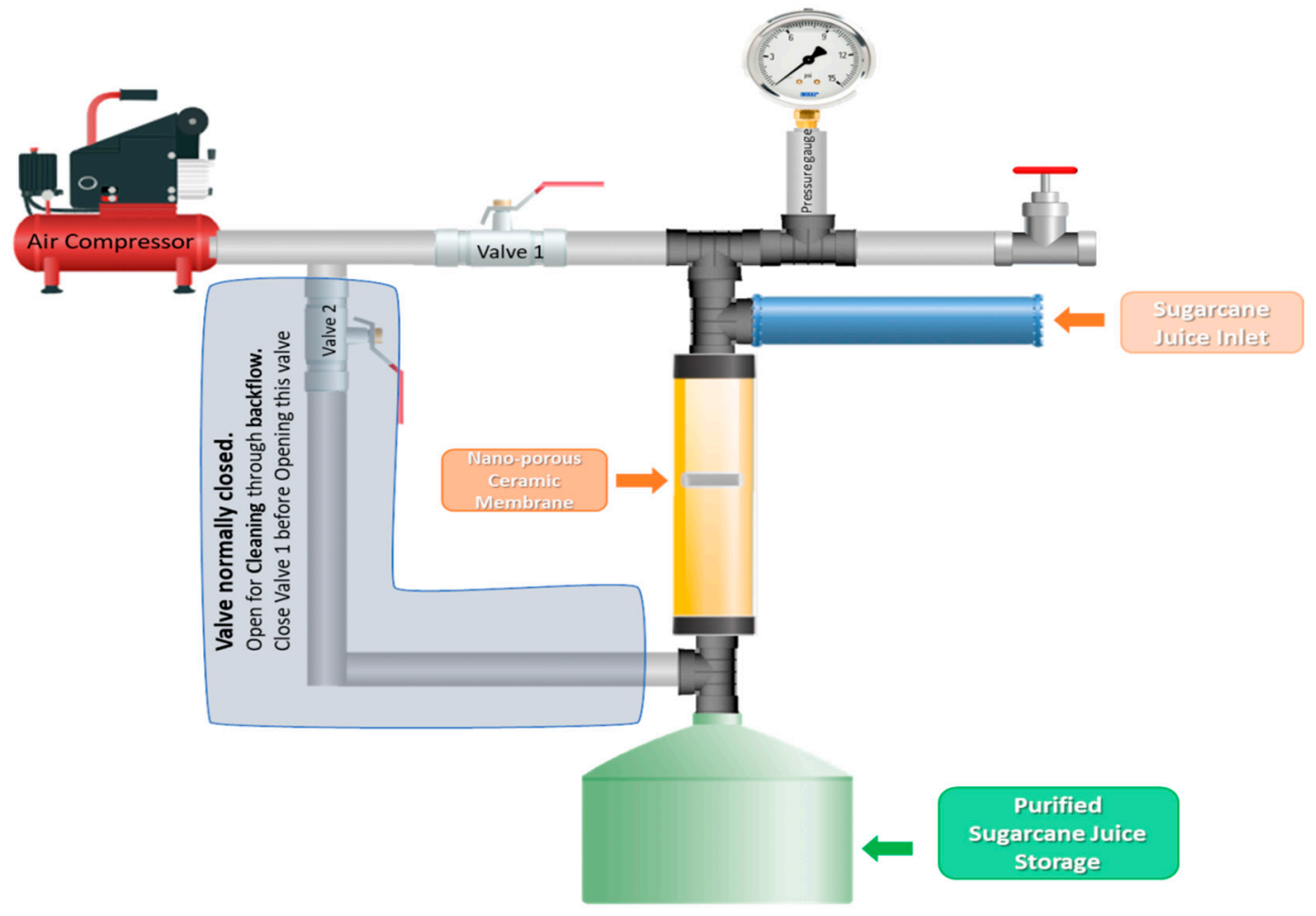

Figure 2. Schematic diagram of the lab-scale ultrafiltration analysis setup.

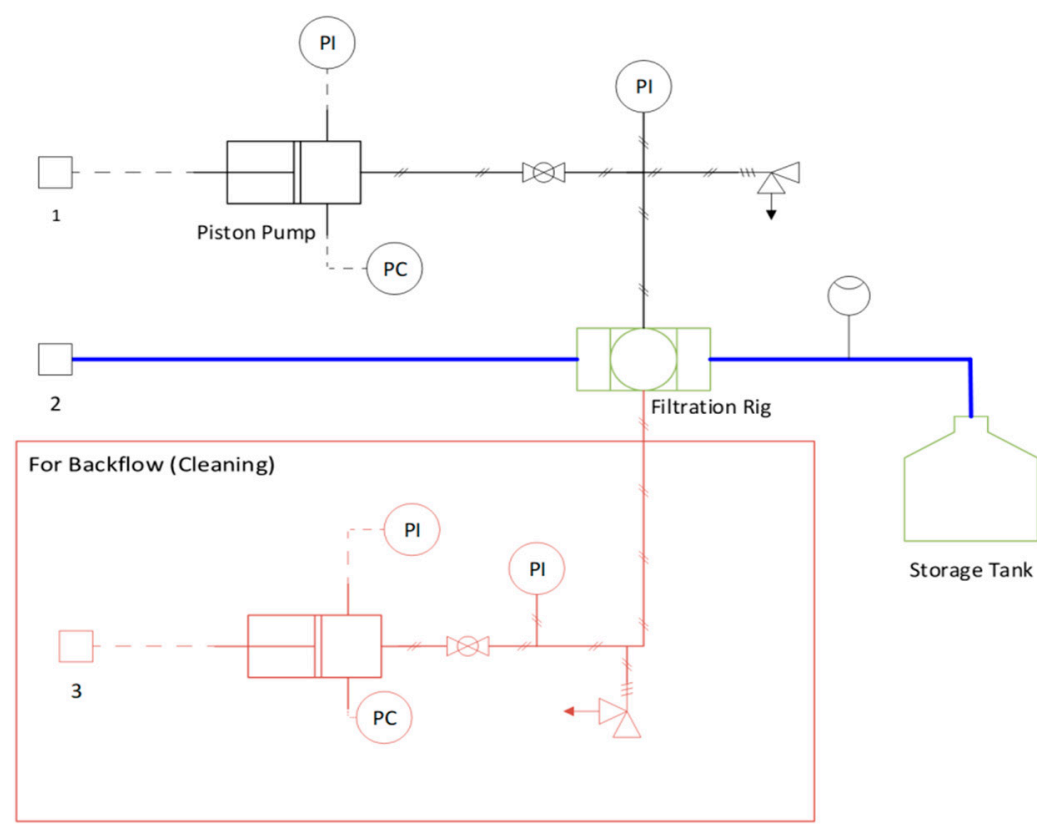

\begin{tabular}{|l|l|}
\hline Sr no. & Utility Connections \\
\hline 1,3 & 12 V 10 Amps Power Supply \\
\hline 2 & Sugarcane Juice Supply tank \\
\hline
\end{tabular}

\begin{tabular}{|c|l|}
\hline \multicolumn{2}{|l|}{ Legend } \\
\hline & Main Process line \\
\hline & Pneumatic Signal \\
\hline & Electrical Signal \\
\hline & Pressure Indicator \\
\hline \\
\hline
\end{tabular}

Figure 3. Piping and instrumentation (P\&ID) diagram of the lab-scale ultrafiltration analysis setup.

\subsection{Ultrafiltration Performance Testing}

Ultrafiltration performance tests were carried out on the lab-scale setup by the forwardflow of various liquids, including sugarcane, distilled water, tap water, and muddy water, through the filter and reverse flow for cleaning the filter. During the forward-flow operation, the unfiltered solutions were pumped through the inlet pipe, with the other end of the pipe connected to a storage container (measuring cylinder). Pressure was then applied using the air compressor with the forward valve (valve 1) open and the backward valve (valve 2) closed. With time, the debris of the residue started filling the pores of the filter. To prevent 
an undesired drop in the flow rate, a backwards-flow operation was also performed. For this purpose, the air compressor was connected to a pipe leading to the forward valve, but it split before the valve towards a backwards-flow loop. Referring to the process flow diagram (Figure 2), the backwards-flow loop is highlighted in red. To perform a backwards-flow operation, the air compressor, along with the rest of the operation, was shut down. The forward valve, the joint between the main piping and the storage container, and the solution inlet were kept closed, and the backward valve was kept open. Through this setup, a time-motion study was carried out, and the average flow rates of all liquids were determined.

\section{Results and Discussion}

\subsection{Morphology and Crystallinity of Standard Alumina Nano-Powder}

The SEM micrograph of the alumina nano-powder is illustrated in Figure 4, whereas the corresponding XRD spectrum of the powder is presented in Figure 5. The SEM micrographs showed that the alumina nano-powder possessed spherical-shaped particles of a size ranging from roughly $27.49-50 \mathrm{~nm}$. Spherical and uniform particle sizes are essential for obtaining pores of a uniform size through partial sintering. Membranes with a uniform porosity can lead to better filtration results. The XRD spectrum revealed that the powder consisted of alpha phase and validated the purity by demonstrating various intensity peaks for alumina and no intensity peak for any other element (Figure 5).

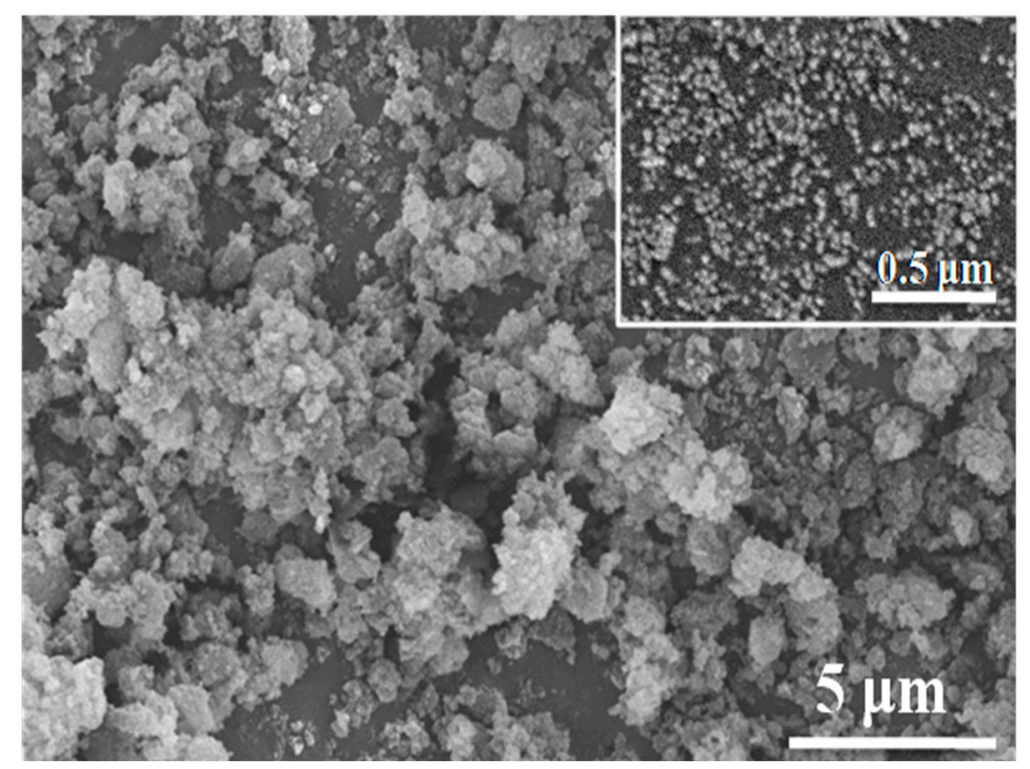

Figure 4. SEM micrograph of alumina nano-powder taken at 5000× magnification (inset: SEM micrograph of the same powder taken at 30,000 $\times$ magnification). 


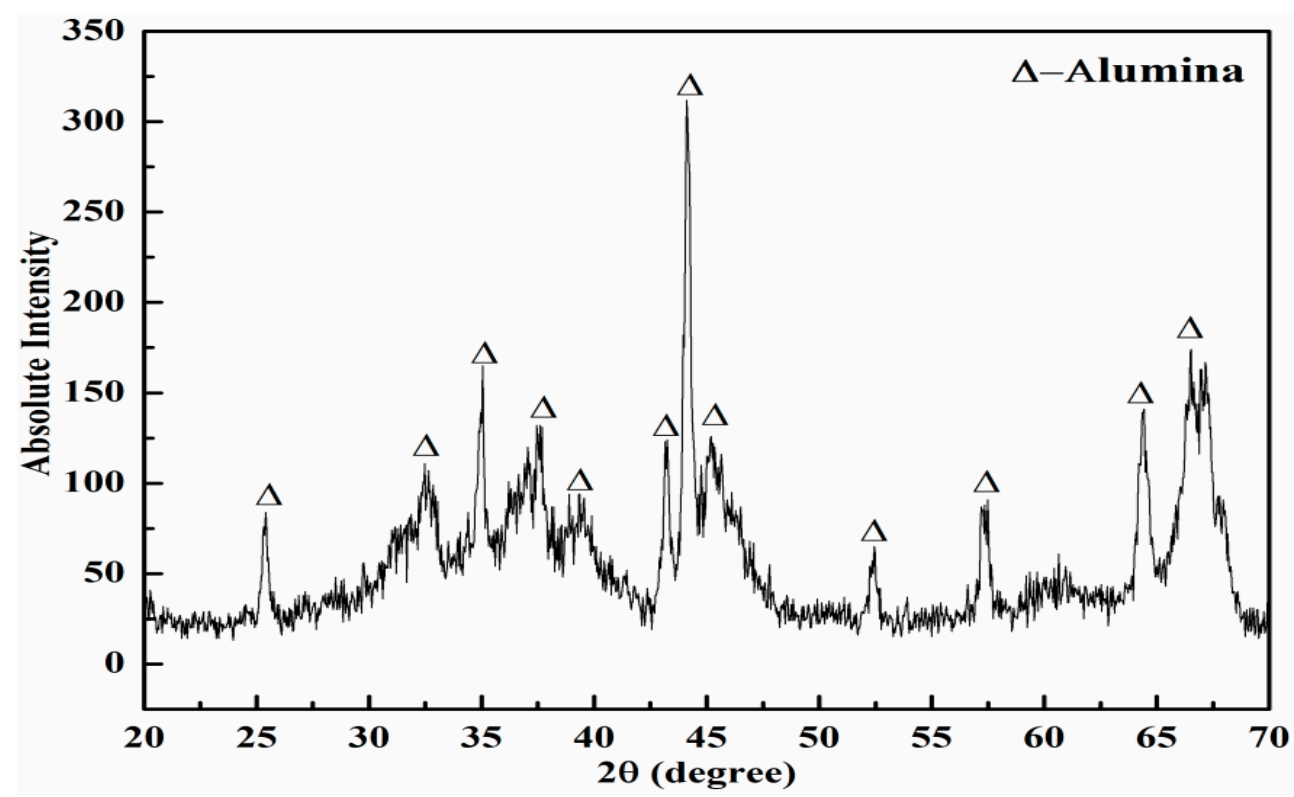

Figure 5. XRD spectrum of the alumina nano-powder.

\subsection{Morphology of Alumina Membranes}

The morphologies of all the alumina membranes, captured from both the cross-section and surface, fabricated by compaction and sintering at various temperatures, ranging from $1200-1300{ }^{\circ} \mathrm{C}$ for different times ranging from $5-15 \mathrm{~h}$, are illustrated in Figures 6 and 7 , whereas the corresponding average pore sizes, measured by SEM, are plotted in Figure 8.
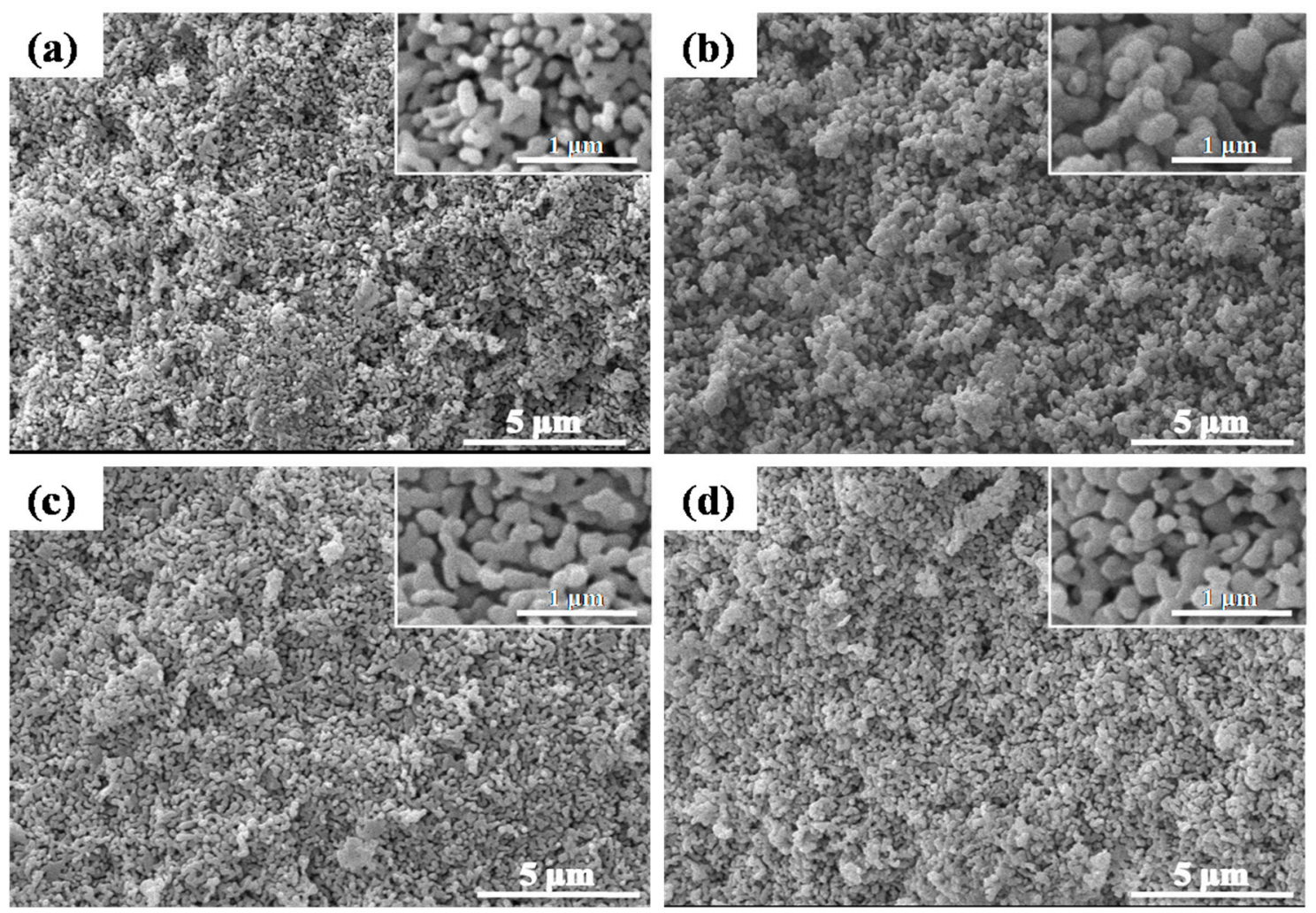

Figure 6. SEM micrographs of alumina membranes, fabricated by compaction and sintering at $1200^{\circ} \mathrm{C}$ for $5 \mathrm{~h}$. (a) Membrane surface and (b) membrane cross-section at $1250^{\circ} \mathrm{C}$ for $5 \mathrm{~h}$; (c) membrane surface and (d) membrane cross-section. 

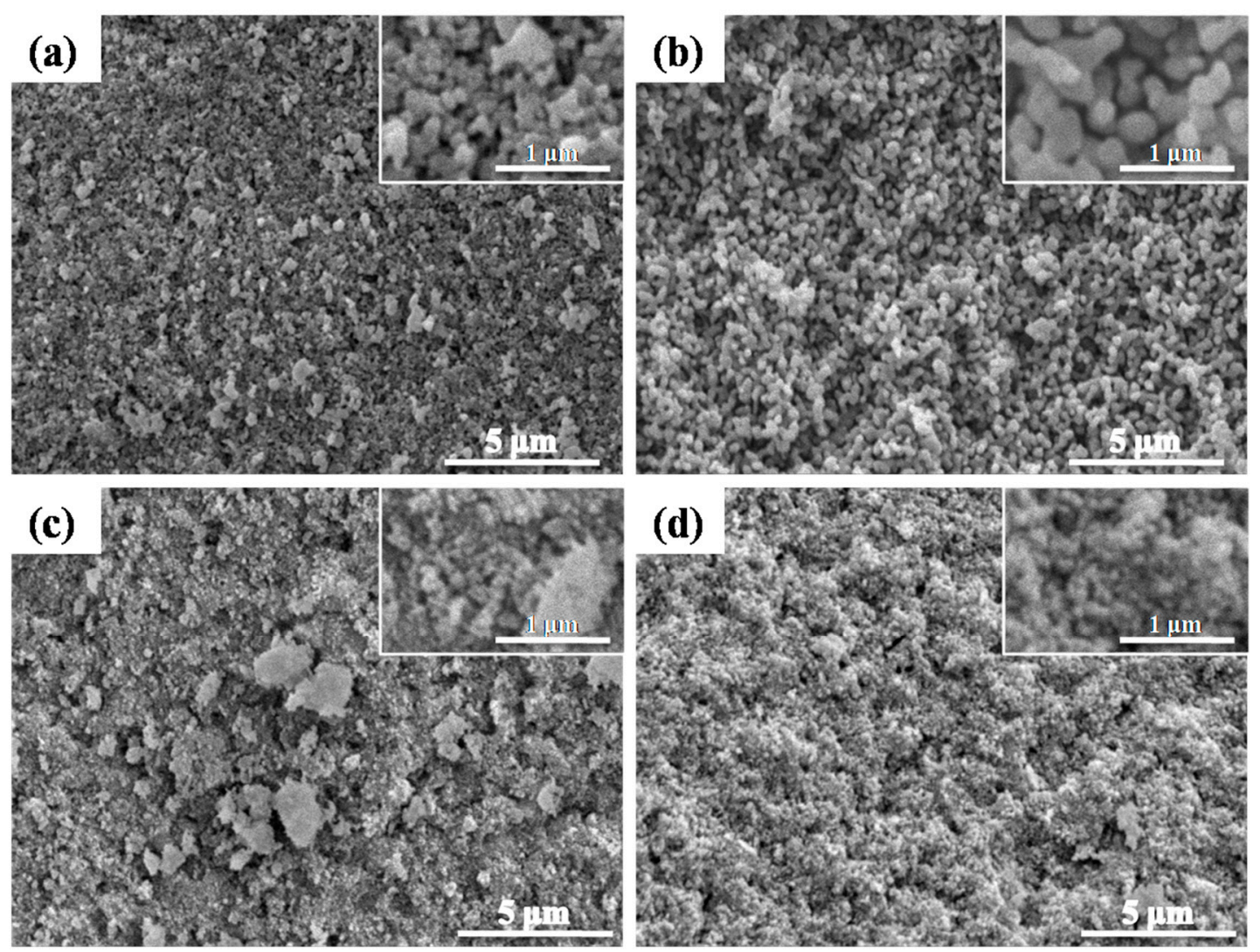

Figure 7. SEM micrographs of alumina membranes, fabricated by compaction and sintering at $1250{ }^{\circ} \mathrm{C}$ for $15 \mathrm{~h}$. (a) Membrane surface and (b) membrane cross-section and at $1300{ }^{\circ} \mathrm{C}$ for $5 \mathrm{~h}$; (c) membrane surface and (d) membrane cross-section.
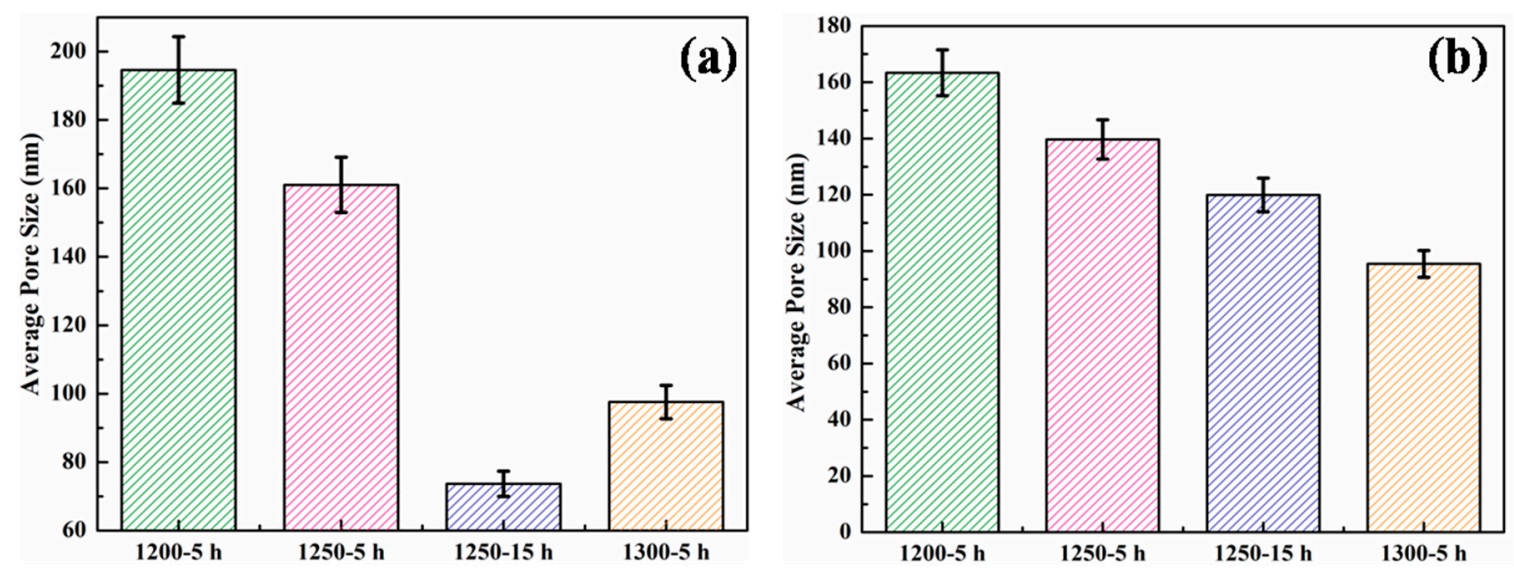

Figure 8. Average pore size as a function of the sintering temperature/time measured from (a) the membrane surface and (b) membrane cross-section.

SEM micrographs demonstrated a clear inter-connectivity between the pores and an open network of porosity in all the fabricated samples. All the membranes showed a consistent gradual increase in pore size from the surface towards the center of the membrane, with the necessary open porosity for filtration. This is explained by the fact that sintering proceeds from outside when performed in Joule heating. $\mathrm{Al}_{2} \mathrm{O}_{3}$, inherently an insulator, is expected to undergo slight thermal variations when subjected to relatively faster sintering routes for shorter times. A slight differential heating of the samples can lead to differences in sintering rates and densification from the surface to the bulk. In the figures shown below, this effect is highlighted in terms of a difference in the average pore size of the samples. 
A gradual decrease in average pore sizes was observed with the increase in sintering temperature, as well as time. The sample sintered at $1200^{\circ} \mathrm{C}$ for $5 \mathrm{~h}$ exhibited the highest average pore sizes from both the surface $(194.65 \mathrm{~nm})$ and cross-section $(163.38 \mathrm{~nm})$. The sample sintered at $1250{ }^{\circ} \mathrm{C}$ for $5 \mathrm{~h}$ demonstrated a $17 \%$ reduction in pore size at the surface and an overall $15 \%$ reduction from the cross-section, compared to the sample sintered at $1200{ }^{\circ} \mathrm{C}$ for $5 \mathrm{~h}$. Working with a smaller initial particle size leads to a higher thermodynamic tendency for particles to coalesce. Additionally, the higher sphericity of very fine particles increases the neck curvature. A higher neck curvature further accelerates the initial sintering kinetics. Keeping the time and particle size constant, higher sintering temperatures lead to higher values of potential energy and atomic fluxes, resulting in a higher densification of the samples. This trend is evident from the microstructures of the samples, which indicate an overall reduction in the average pore size with increasing temperature. A significant $(62 \%)$ reduction in pore size was observed at the surface of the membranes sintered at $1250{ }^{\circ} \mathrm{C}$ for $15 \mathrm{~h}$, whereas a $27 \%$ reduction in pore size was observed at the cross-section of this membranes, compared to the membrane sintered at $1200{ }^{\circ} \mathrm{C}$ for $5 \mathrm{~h}$.

Similarly, the alumina membrane sintered at $1300{ }^{\circ} \mathrm{C}$ for $5 \mathrm{~h}$ also demonstrated a considerable $50 \%$ reduction in pore size from the surface and a $42 \%$ reduction from the cross-section. The optimum results for the average pore size were obtained in the alumina membrane sintered at $1250{ }^{\circ} \mathrm{C}$ for $15 \mathrm{~h}$. Therefore, this membrane was selected to evaluate the ultrafiltration performance.

The sintering process proceeds from outside to inside in this mode of heating. The surface gets heated more, as compared to the bulk, due to the lower thermal conductivity of alumina. Therefore, the bulk will be comparatively less sintered, as compared to the surface. A differential in the degree of sintering results in a difference in pore sizes.

\subsection{Compressive Properties}

Compression testing of all the alumina membranes was carried out to determine the membrane with the optimum strength under high-pressure working conditions. The stress-strain curves obtained after compression testing are plotted in Figure 9, whereas the obtained values of maximum stress and maximum strain are tabulated in Table 1. Modest values of maximum stress $(0.206 \mathrm{MPa})$, maximum strain $(2.404 \%)$, and modulus were exhibited by the alumina membrane sintered at $1200{ }^{\circ} \mathrm{C}$ for $5 \mathrm{~h}$. This is attributed to the higher pore size and lower densification, which allowed the membrane to bear the moderate stress and exhibit a moderate strain [36].

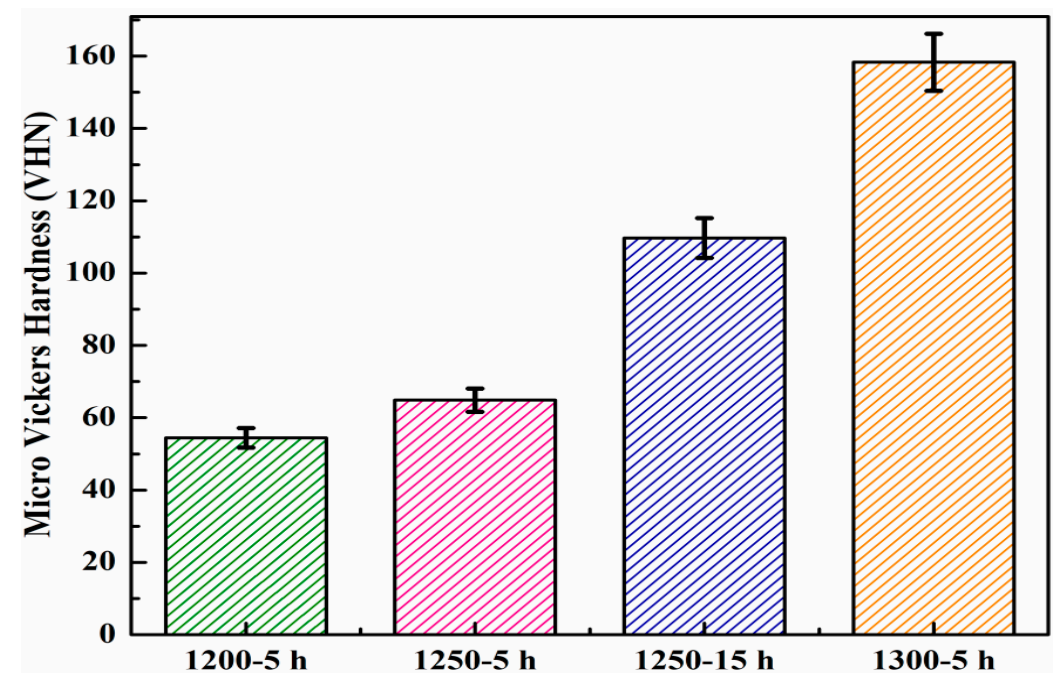

Figure 9. Micro Vickers hardness values of nanoporous alumina membranes. 
On the other hand, the alumina membrane sintered at $1250{ }^{\circ} \mathrm{C}$ for $5 \mathrm{~h}$ exhibited the lowest value of maximum stress of $0.141 \mathrm{MPa}$, as well as modulus, and demonstrated the highest value of maximum strain of $3.694 \%$ among all the membranes. The initial drop in their values at a strain of around 1\% highlights that the fracture has already taken place. Because they are so loosely bound, they still keep on compressing after an initial drop in the stress value. Here, the initial drop is more important and signifies that a fracture of the membrane has already taken place. Similarly, the membranes sintered at $1250{ }^{\circ} \mathrm{C}$ for $15 \mathrm{~h}$ and $1300{ }^{\circ} \mathrm{C}$ for $5 \mathrm{~h}$ exhibited relatively higher values of maximum stress (0.373 $\mathrm{MPa}, 0.488 \mathrm{MPa})$ and modulus, and lower values of maximum strain $(2.195 \%$, $2.272 \%$ ), compared to membranes sintered at $1200{ }^{\circ} \mathrm{C}$ and $1250{ }^{\circ} \mathrm{C}$ for $5 \mathrm{~h}$. This is because increasing the sintering temperature/time increased the densification, which gradually reduced the pore size and eliminated the porosity. Due to a reduction in the average pore size, the membranes bear relatively higher stress and exhibit lower strain values [37].

\subsection{Micro Vickers Hardness}

Variations in the micro Vickers hardness values of the alumina membranes, fabricated by sintering at various temperatures ranging from $1200-1300{ }^{\circ} \mathrm{C}$ for different times ranging from $5-15 \mathrm{~h}$, are plotted in Figure 9. The alumina membrane sintered at $1200{ }^{\circ} \mathrm{C}$ for $5 \mathrm{~h}$ exhibited the lowest 54.46 VHN micro Vickers hardness value, associated with a higher pore size and lower densification of this membrane among all the tested membranes [36]. With the increase of the sintering temperature to $1250^{\circ} \mathrm{C}$, the micro Vickers hardness value was observed to increase by $19 \%$, attributed to the decrease in pore size and increase in densification [36]. Similarly, with the increase in the sintering time to $15 \mathrm{~h}$ by maintaining the same sintering temperature $\left(1250{ }^{\circ} \mathrm{C}\right)$, a $100 \%$ increased Vickers hardness was achieved, compared to the membrane sintered at $1200{ }^{\circ} \mathrm{C}$ for $5 \mathrm{~h}$. On the other hand, the alumina membrane sintered at $1300{ }^{\circ} \mathrm{C}$ for $5 \mathrm{~h}$ demonstrated the highest (158.3 VHN) micro Vickers hardness among all the membranes, which was associated with the lowest pore size and highest densification [37].

\subsection{Ultrafiltration Performance}

To evaluate the ultrafiltration performance, the alumina membrane with the lowest pore size of $73.65 \mathrm{~nm}$, obtained after sintering at $1250{ }^{\circ} \mathrm{C}$ for $15 \mathrm{~h}$, was selected as the filter. A time motion study was carried out, and the average flow rates were measured by passing various liquids, including sugarcane juice, distilled water, tap water, and muddy water, at a pressure of 8-9 bars through the selected alumina membrane. The time-motion study graph and average flow rates, as a function of the volume of liquids, are presented in Figures 10 and 11, respectively. The time motion study demonstrated that the selected alumina membrane performed very well in the ultrafiltration of sugarcane juice, compared to the other liquids. The maximum volume of sugarcane was passed, whereas relatively very low volumes of other liquids were passed through this membrane, as illustrated in Figure 10.

On the contrary, sugarcane juice demonstrated the lowest average flow rate, and distilled water showed the highest average flow rate among all liquids, as illustrated in Figure 11. This might be due to the density of the sugar cane juice, which has the highest amount of impurities, including albumen, phosphates, and $u$ complex organic substances, compared to the other fluids. 


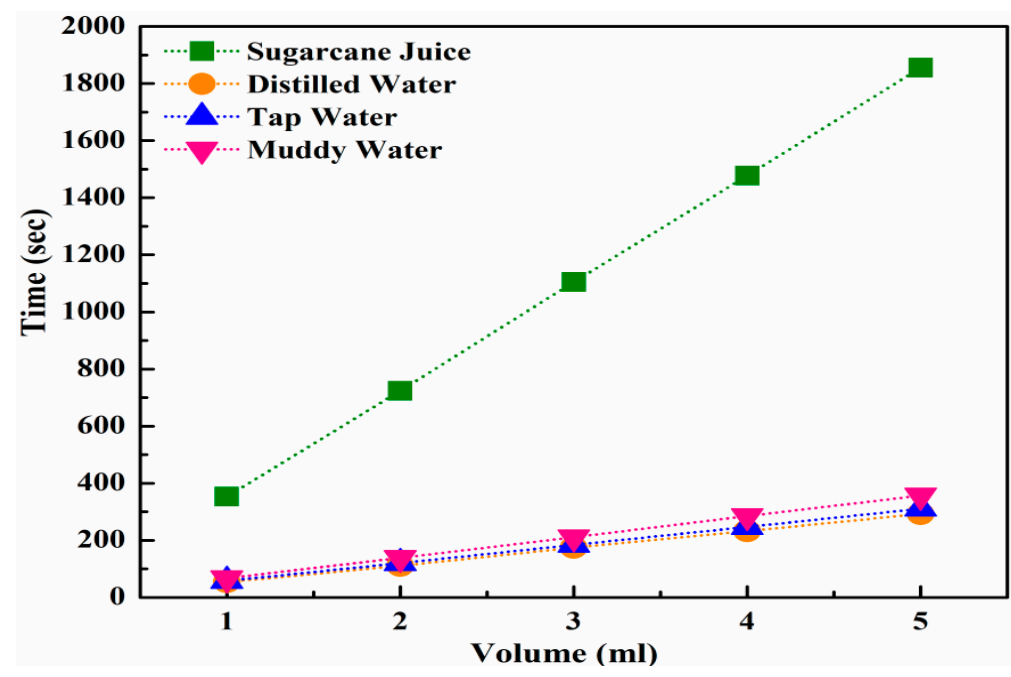

Figure 10. Time-motion study of various sugar industry liquids through a nanoporous alumina membrane.
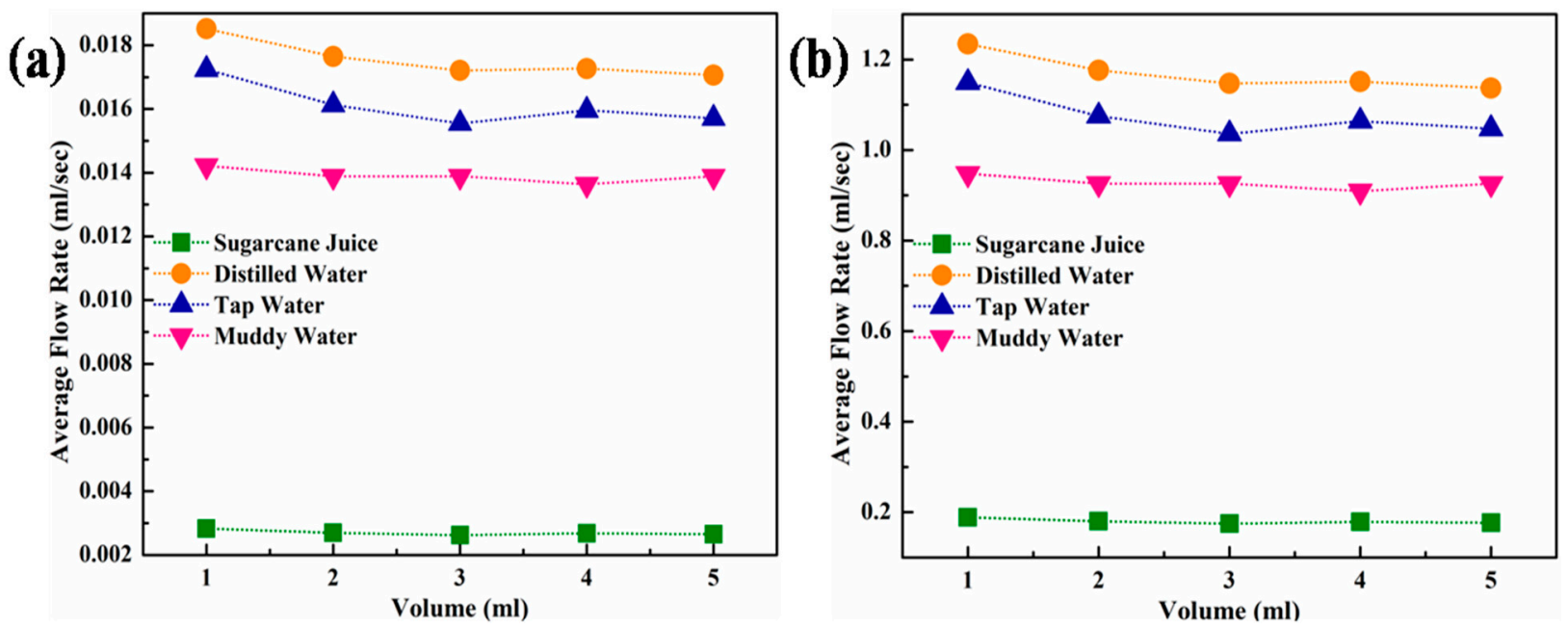

Figure 11. (a) Average flow rate as a function of the volume of various sugar industry liquids passed through a nanoporous alumina membrane and (b) an extrapolated graph of "a" for an industrial alumina membrane with a length of $1000 \mathrm{~mm}$ and diameter of $30 \mathrm{~mm}$.

Sugarcane juice, before and after ultrafiltration through the selected alumina membrane, is illustrated in Figure 12. It was observed that before ultrafiltration, the colour of sugarcane juice was yellowish. This yellowish colour was due to the presence of various natural compounds that are present in the sugarcane juice. The presence of these compounds, which include chlorophylls, carotenoids (carotenes and xanthophylls), falvonoids, phenolic compounds (basic phenolics, hydroxybenzoic acids, phenylacetic acids, hydroxycinnamic acids), polyphenolic compounds (gallic acid, ellagic acid, and ellagitannin), nitrogenous compounds (amino acids and proteins), melanins, melanoidins, aroma compounds, and caramels, gives rise to the color of the sugarcane [38]. The ultrafiltration process caused a discoloration of the sugarcane juice by filtering the above-stated chemicals. This process presents the filtration capability of the membranes fabricated. 

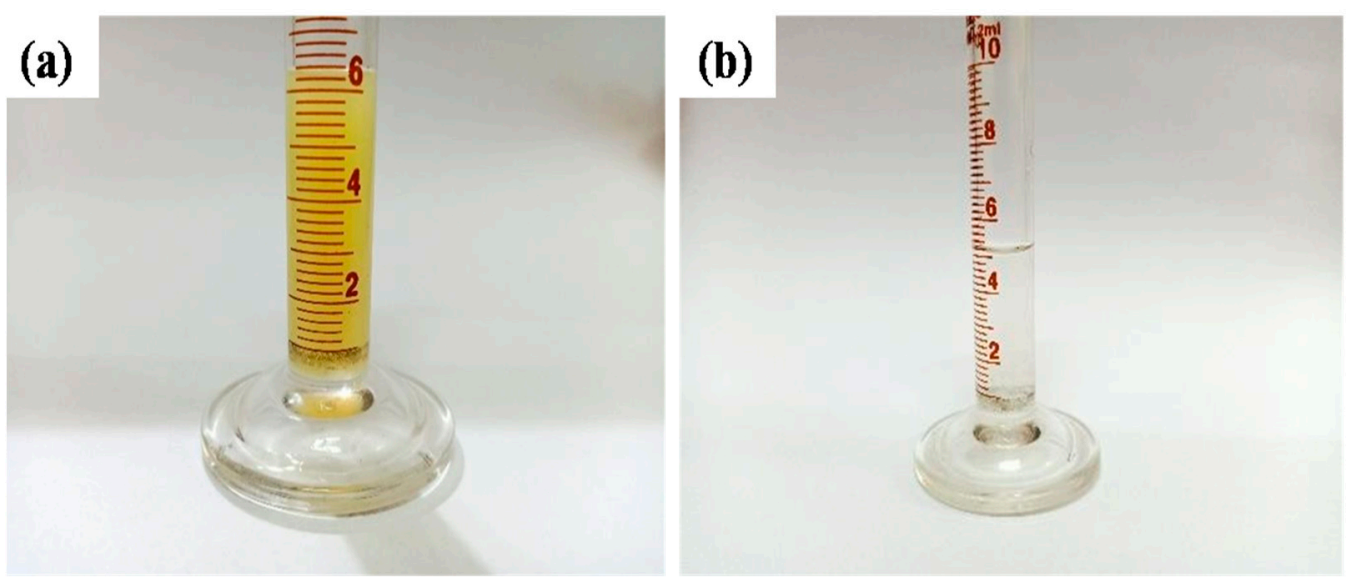

Figure 12. Sugarcane juice (a) before and (b) after ultrafiltration through a nanoporous alumina membrane.

\section{Conclusions}

The ultrafiltration performance of nanoporous alumina membranes produced by sintering for the sugar industry was evaluated. The following conclusions can be drawn from this study:

- The morphologies of all the alumina membranes revealed interconnected pores and an open network of porosity.

- An increase in the sintering temperature/time caused a gradual decrease in the average pore sizes. The highest average pore size was achieved after sintering at $1200{ }^{\circ} \mathrm{C}$ for $5 \mathrm{~h}$, whereas sintering at $1250^{\circ} \mathrm{C}$ for $15 \mathrm{~h}$ produced an alumina membrane with the optimum and lowest pore size.

- The alumina membrane sintered at $1300{ }^{\circ} \mathrm{C}$ for $5 \mathrm{~h}$ demonstrated the highest value of maximum stress, whereas the membrane sintered at $1250{ }^{\circ} \mathrm{C}$ for $5 \mathrm{~h}$ exhibited the highest value of maximum strain among all the membranes. Similarly, the alumina membrane sintered at $1200^{\circ} \mathrm{C}$ for $5 \mathrm{~h}$ exhibited the lowest micro Vickers hardness, whereas the alumina membrane sintered at $1300{ }^{\circ} \mathrm{C}$ for $5 \mathrm{~h}$ demonstrated the highest micro Vickers hardness.

- The alumina membrane with the lowest pore size of $73.65 \mathrm{~nm}$, sintered at $1250{ }^{\circ} \mathrm{C}$ for $15 \mathrm{~h}$, was selected for the evaluation of ultrafiltration performance.

Author Contributions: F.K.N., M.A.U., and A.A. developed the conceptualization and methodology of the study. M.A.H. and Y.-K.P. managed the resources and provided supervision and valuable research insights for the study. Z.K. and M.S.B. provided the literature resources and helped with the analysis. A.R. and X.L. contributed to the writing and provided valuable research insights. All authors have read and agreed to the published version of the manuscript.

Funding: We gratefully acknowledge the support from the Higher Education Commission of Pakistan, under project number HEC-TDF 02-209, and the National Research Foundation of Korea, under the projects, NRF-2020R1I1A1A01072793 and NRF- 2020M1A2A2079801, to publish this work.

Institutional Review Board Statement: Not applicable.

Informed Consent Statement: Not applicable.

Data Availability Statement: The data are provided within the article.

Acknowledgments: We acknowledge the support and assistance provided by Hassan Ali Khan and Asfandyar Malook, affiliated with the School of Chemical and Materials Engineering (SCME), National University of Sciences and Technology.

Conflicts of Interest: The authors declare no conflict of interest. 


\section{References}

1. Wang, K.; Liu, G.; Hoivik, N.; Johannessen, E.; Jakobsen, H. Electrochemical engineering of hollow nanoarchitectures: Pulse/step anodization (Si, Al, Ti) and their applications. Chem. Soc. Rev. 2014, 43, 1476-1500. [CrossRef]

2. So, S.; Lee, K.; Schmuki, P. Ultrafast growth of highly ordered anodic $\mathrm{TiO}_{2}$ nanotubes in lactic acid electrolytes. J. Am. Chem. Soc. 2012, 134, 11316-11318. [CrossRef] [PubMed]

3. Sreekantan, S.; Wei, L.C.; Lockman, Z. Extremely Fast Growth Rate of TiO2 Nanotube Arrays in Electrochemical Bath Containing $\mathrm{H}_{2} \mathrm{O}_{2}$. J. Electrochem. Soc. 2011, 158, C397. [CrossRef]

4. Roy, P.; Berger, S.; Schmuki, P. $\mathrm{TiO}_{2}$ nanotubes: Synthesis and applications. Angew. Chem. Int. Ed. 2011, 50, 2904-2939. [CrossRef] [PubMed]

5. $\quad \mathrm{Gu}$, Q.; Ng, T.C.A.; Zang, W.; Zhang, L.; Lyu, Z.; Zhang, Z.; Ng, H.Y.; Wang, J. Surface engineered alumina microfiltration membranes based on rationally constructed core-shell particles. J. Eur. Ceram. Soc. 2020, 40, 5951-5958. [CrossRef]

6. Saghir, M.; Adeel, M.; Ahmed, A.; Bint, N.; Manzoor, U.; Razzaq, A.; Xian, L.; Mohammad, K.; Shahid, M.; Park, Y. Effect of high energy ball milling and low temperature densi fi cation of plate-like alumina powder. Powder Technol. 2021, 383, 84-92. [CrossRef]

7. Jiang, B.; Guo, Y.; Kim, J.; Whitten, A.E.; Wood, K.; Kani, K.; Rowan, A.E.; Henzie, J.; Yamauchi, Y. Mesoporous Metallic Iridium Nanosheets. J. Am. Chem. Soc. 2018, 140, 12434-12441. [CrossRef]

8. Najam, M.; Hussain, M.; Ali, Z.; Maafa, I.M.; Akhter, P.; Majeed, K.; Ahmed, A.; Shehzad, N. Influence of silica materials on synthesis of elastomer nanocomposites: A review. J. Elastomers Plast. 2019. [CrossRef]

9. Yang, W.; Li, C.; Tian, S.; Liu, L.; Liao, Q. Influence of synthesis variables of a sol-gel process on the properties of mesoporous alumina and their fluoride adsorption. Mater. Chem. Phys. 2020, 242, 122499. [CrossRef]

10. Cheng, H.; Lijie, L.; Wang, B.; Feng, X.; Mao, Z.; Vancso, G.J.; Sui, X. Multifaceted applications of cellulosic porous materials in environment, energy, and health. Prog. Polym. Sci. 2020, 106, 101253. [CrossRef]

11. Tavolaro, A.; Drioli, E. Zeolite membranes. Adv. Mater. 1999, 11, 975-996. [CrossRef]

12. Zawrah, M.F.; Khattab, R.M.; Girgis, L.G.; El Shereefy, E.E.; Abo Sawan, S.E. Effect of CTAB as a foaming agent on the properties of alumina ceramic membranes. Ceram. Int. 2014, 40, 5299-5305. [CrossRef]

13. Ng, L.Y.; Mohammad, A.W.; Leo, C.P.; Hilal, N. Polymeric membranes incorporated with metal/metal oxide nanoparticles: A comprehensive review. Desalination 2013, 308, 15-33. [CrossRef]

14. Tang, C.M.; Li, X.L. Separative capability of $\gamma$-Al2O3 porous ceramic membrane modified by ZIF-8. Korean J. Chem. Eng. 2013, 30, 1119-1124. [CrossRef]

15. Van Heetvelde, P.; Beyers, E.; Wyns, K.; Adriaensens, P.; Maes, B.U.W.; Mullens, S.; Buekenhoudt, A.; Meynen, V. A new method to graft titania using Grignard reagents. Chem. Commun. 2013, 49, 6998-7000. [CrossRef] [PubMed]

16. Chen, M.; Shang, R.; Sberna, P.M.; Luiten-Olieman, M.W.J.; Rietveld, L.C.; Heijman, S.G.J. Highly permeable silicon carbidealumina ultrafiltration membranes for oil-in-water filtration produced with low-pressure chemical vapor deposition. Sep. Purif. Technol. 2020, 253, 117496. [CrossRef]

17. Khanmohammadi, S.; Taheri-Nassaj, E.; Farrokhi-Rad, M. Synthesis of meso-porous gamma-alumina membrane: Effect of yttria addition on the thermal stability. Surf. Interfaces 2020, 21, 100683. [CrossRef]

18. Jingxian, Z.; Dongliang, J.; Weisensel, L.; Greil, P. Deflocculants for tape casting of $\mathrm{TiO}_{2}$ slurries. J. Eur. Ceram. Soc. 2004, 24, 2259-2265. [CrossRef]

19. Wei, C.C.; Chen, O.Y.; Liu, Y.; Li, K. Ceramic asymmetric hollow fibre membranes-One step fabrication process. J. Memb. Sci. 2008, 320, 191-197. [CrossRef]

20. Patel, F.; Baig, M.A.; Laoui, T. Processing of porous alumina substrate for multilayered ceramic filter. Desalin. Water Treat. 2011, 35, 33-38. [CrossRef]

21. Eom, J.H.; Kim, Y.W.; Raju, S. Processing and properties of macroporous silicon carbide ceramics: A review. J. Asian Ceram. Soc. 2013, 1, 220-242. [CrossRef]

22. Kikkinides, E.S.; Stoitsas, K.A.; Zaspalis, V.T.; Burganos, V.N. Simulation of structural and permeation properties of multi-layer ceramic membranes. J. Memb. Sci. 2004, 243, 133-141. [CrossRef]

23. Zhou, S.; Xue, A.; Zhao, Y.; Li, M.; Wang, H.; Xing, W. Grafting polyacrylic acid brushes onto zirconia membranes: Fouling reduction and easy-cleaning properties. Sep. Purif. Technol. 2013, 114, 53-63. [CrossRef]

24. Rezaei Hosseinabadi, S.; Wyns, K.; Meynen, V.; Carleer, R.; Adriaensens, P.; Buekenhoudt, A.; Van der Bruggen, B. Organic solvent nanofiltration with Grignard functionalised ceramic nanofiltration membranes. J. Memb. Sci. 2014, 454, 496-504. [CrossRef]

25. Mahesh Kumar, S.; Roy, S. Filtration characteristics in dead-end microfiltration of living Saccharomyces cerevisiae cells by alumina membranes. Desalination 2008, 229, 348-361. [CrossRef]

26. Ishak, N.F.; Hashim, N.A.; Othman, M.H.D. Antifouling properties of hollow fibre alumina membrane incorporated with graphene oxide frameworks. J. Environ. Chem. Eng. 2020, 8. [CrossRef]

27. Hashimoto, H.; Kojima, S.; Sasaki, T.; Asoh, H. $\alpha$-Alumina membrane having a hierarchical structure of straight macropores and mesopores inside the pore wall. J. Eur. Ceram. Soc. 2018, 38, 1836-1840. [CrossRef]

28. Peng Lee, K.; Mattia, D. Monolithic nanoporous alumina membranes for ultrafiltration applications: Characterization, selectivitypermeability analysis and fouling studies. J. Memb. Sci. 2013, 435, 52-61. [CrossRef]

29. Ishak, N.F.; Hashim, N.A.; Othman, M.H.D.; Monash, P.; Zuki, F.M. Recent progress in the hydrophilic modification of alumina membranes for protein separation and purification. Ceram. Int. 2017, 43, 915-925. [CrossRef] 
30. Bhattacharya, P.K.; Agarwal, S.; De, S.; Rama Gopal, U.V.S. Ultrafiltration of sugar cane juice for recovery of sugar: Analysis of flux and retention. Sep. Purif. Technol. 2001, 21, 247-259. [CrossRef]

31. Kishihara, S.; Fujii, S.; Komoto, M. Ultrafiltration of cane juice: Influence of flux and quality of permeate. Int. Sugar J. 1981, 83, 35.

32. Gekas, V.; Hallstorm, B.; Tragardh, G. Food and Diary applications: The state of art. Desalination 1985, 53, 95-127. [CrossRef]

33. Neilsen, W.K.; Kriesten, S.; Madsen, R.F. Prospects and possibilities in the application of membrane filtration systems within the beet and sugar industry. Sugar Technol. Rev. 1982, 9, 52.

34. Trägårdh, G.; Gekas, V. Membrane technology in the sugar industry. Desalination 1988, 69, 9-17. [CrossRef]

35. Khulbe, K.; Feng, C.Y.; Matsuura, T. Synthetic Polymeric Membranes; Springer: Berlin/Heidelberg, Germany, 2008 ; pp. 101-139.

36. Li, L.; Chen, M.; Dong, Y.; Dong, X.; Cerneaux, S.; Hampshire, S.; Cao, J.; Zhu, L.; Zhu, Z.; Liu, J. A low-cost alumina-mullite composite hollow fiber ceramic membrane fabricated via phase-inversion and sintering method. J. Eur. Ceram. Soc. 2016, 36, 2057-2066. [CrossRef]

37. Barma, S.; Mandal, B. Effects of sintering temperature and initial compaction load on alpha-alumina membrane support quality. Ceram. Int. 2014, 40, 11299-11309. [CrossRef]

38. Nguyen, D.M.T. Colour Removal from Sugar Cane Juice. PhD Thesis, Queensland University of Technology, Brisbane City, QLD, Australia, 2013. 